\title{
In Shanghe County Economic Development as an Example Based on Location Entropy Method Comparative Advantage Analysis
}

\author{
Wang Dongling \\ Department of economics and management, Shandong Yingcai University, Jinan, 251400, China \\ email: 40668058@qq.com,
}

\section{Keywords: Location Quotient;Comparative Advantage;Economic Development}

\begin{abstract}
International and regional comparative advantage is the foundation of economic exchanges and cooperation, is under the condition of economic regionalization and globalization can be the basis of mutual benefit and win-win. The production and export of countries and regions have a comparative advantage of products or services, imported themselves do not have advantage of the products and services, not only good for themselves, but also good for others, is more advantageous to regional and global.Seize the comparative advantage, is the most backward developing regions can seize the opportunity successfully.Professor Lin etc. Put forward the strategy of "comparative advantage" more centrally embodies the spirit of this.It is the most worthy of the core content, "the economic development in every stage can exert the comparative advantages of the resources endowment, so as to maintain sustained economic growth and upgrade the structure of resources endowment", for the majority of the development of regional economy, is of high significance.This paper is to use comparative advantage analysis method, analyzes the industrial structure of Shanghe research.
\end{abstract}

\section{Location entropy method is introduced}

Rate of location entropy is also called specialization. The ratio of the so-called entropy, is ratio. It by Mr Geithner (P.H aggett) first put forward and applied to the location in the analysis. Location entropy in measuring ingredients in the area of space distribution, reflect a certain degree of sector specialization, as well as an area in the region of the high level of position and function, etc., is a very meaningful indicators. In the study of the industrial structure, using location entropy index is mainly to analyze the status of regional leading specialized departments.

In this paper, using the method of location entropy, to provide the added value of existing statistical data as the foundation, processing industry generated shanghe region "relative share index, which reflect the market competitiveness of shanghe industry, achieve the goal of identifying regional comparative advantage. Location entropy method is used to measure the spatial analysis of the various objects relative distribution method, and the analysis conclusion is shown by a relative share index, namely the location quotient value. Shanghe the added value of industrial output value of $\mathrm{J}$ K share in the gross national product (GNP) and Jinan the industry of the proportion of GDP than the industry location quotient value.

$$
L Q_{i j}=\frac{L_{i j} / \sum_{j} L_{i j}}{\sum_{i j} L_{i j} / \sum_{i} \sum_{j} L_{i j}}
$$

Type in the $\mathrm{i}$ - in the region $\mathrm{i}$;

Type in the $\mathrm{j}$ - in the industry $\mathrm{j}$.

$\mathrm{L}_{\mathrm{ij}}$ - the ith a region first $\mathrm{j}$ a industry output index;

$\mathrm{LQ}_{\mathrm{il}}$ - I region j industry location entropy;

Generally, LQ>1, show $\mathrm{M}$ industry in the region more than the overall level of specialization degree and the professional industry belongs to the region, the industry has a comparative advantage, the industry or its products can be external expansion or output, The greater the value of the NO, the greater the specialization level is higher, the greater the comparative advantage. The LQ 
$=1$, M shows that the region industry specialization level and the overall level. $\mathrm{LQ}<1$, $\mathrm{M}$ shows that the region industry specialization level is lower than the overall level, its size is more vulnerable. LQ value is smaller, more vulnerable, the more obvious, means the industry's output in the region can't meet the needs of the region, from the area outside the introduction of the industry or input $\mathrm{M}$ industrial products to meet the needs of the region.

\section{Based on the location entropy method of Shanghe three big industry's comparative advantage}

(a) Shanghe economic development

The overall level of regional economic development of Jinan in Shandong province are among the best, but the unbalanced regional economic development of Jinan, according to statistics, in 2011 the GDP reached 56.05 billion yuan of Jinan tianqiao area, growth rate reached $12.1 \%$, ranked sixth in the province's 147 counties, and the extreme north of Jinan city Shanghe GDP is only 8.05 billion yuan, the growth rate of $14.3 \%$, ranked seventh in the province's 147 counties (source: Shandong province bureau of statistics web site). Coordinated development of regional economy can shorten the gap between urban and rural areas, with the rapid development of the economy as a whole are related. To promote the development of Shanghe economic relationship between the effective implementation of the Jinan city space layout strategy. In Jinan shibei across the development of the macro environment, in order to further accurately in low economic development zone - shanghe economic operation situation, looking for the economic development of the breakthrough point.

Table 1 in 2011, Jinan, Shanghe industries output value (\$one hundred million)

\begin{tabular}{|c|c|c|c|c|}
\hline & GDP & $\begin{array}{c}\text { The first } \\
\text { industry }\end{array}$ & $\begin{array}{c}\text { The second } \\
\text { industry }\end{array}$ & $\begin{array}{c}\text { The third } \\
\text { industry }\end{array}$ \\
\hline Shanghe & 113.2 & 36.1 & 42.5 & 34.6 \\
\hline Jinan & 4406.29 & 237.86 & 1828.97 & 2339.46 \\
\hline
\end{tabular}

\section{Data sources: Jinan statistical yearbook, 2011, China statistical yearbook, 2011}

Using the data in the table 1 , according to the above formula calculated Shanghe location entropy of each industry, the result is shown in figure, the figure in the radius of the shaft location entropy scale marks Shanghe each industry.

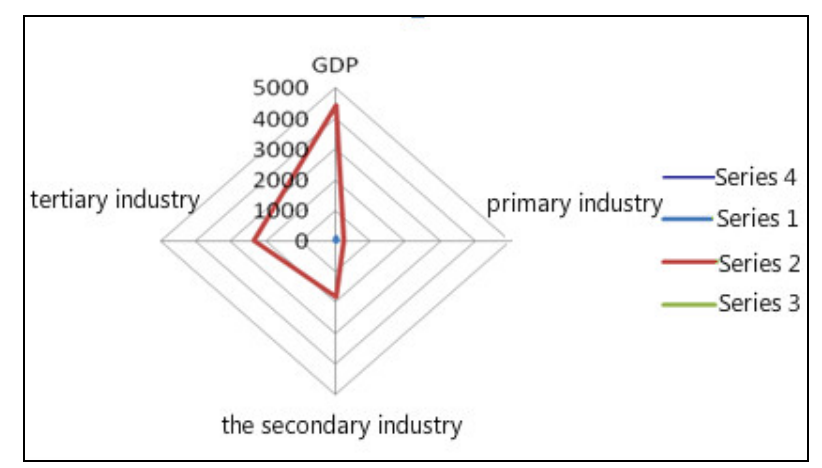

From the results that Jinan first industry location entropy is 0.51 ; The second industry location entropy is 0.47 ; The third industry of location entropy is 0.23 . Shanghe the first and second industry is relatively developed, has a comparative advantage, it had a lot to do with the position areaShanghe, Shanghe has been a large agricultural county, the county income in GDP $30 \%$ of revenue comes from agriculture. Shanghe county is rich in geothermal resources and other Shanghe government use of abundant geothermal resources for investment promotion and capital introduction, such as cultivating blue flower planting base. The third industry entropy value is lower, 
no significant industrial advantage. But because of Shanghe at present the first, second and third industry entropy values are obviously on the low side, so may safely draw the conclusion that Shanghe the overall economic development level is low, the three major industries development not balanced, in the trough of economic development zone in Shandong Province.

(2) three types of Shanghe economic development industry internal structure analysis

Calculated location entropy of Shanghe agriculture is 1.2, the forestry of location entropy is 0.54 , location entropy is 0.57 , animal husbandry, fishery location entropy of 0.1 can be seen from the above results of Shanghe fishery development lags behind, it has to do with is located in the inland, the first in the industry agriculture development relative advantages, advantage industry in Shandong Province, animal husbandry and forestry development in line with the level of Shandong Province.

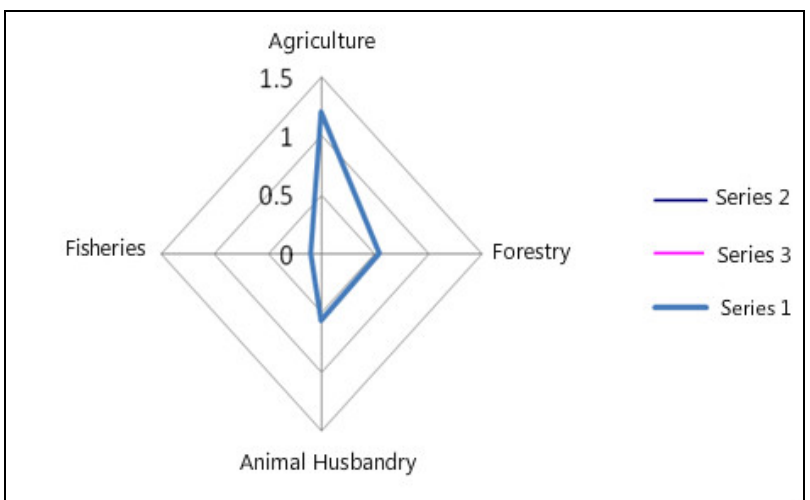

(3) the second industry internal structure analysis

Below reflect the internal structure of the second industry Shanghe, Jiyang extractive industries and gas and water production and supply of locational daqo in 1, has obvious comparative advantage, because Shanghe geothermal resources and the oil-rich impetus to the development of local mining, moreover Shanghe county government in economic development train of thought on the stick to lay a solid foundation to introduce industry, so its infrastructure including electricity, water supply is stable. Industrial and construction of location entropy are respectively 0.8 and 0.83 , average close to Jinan, basic can meet the needs of this region. Manufacturing industry location quotient of the lowest, at 0.3268 is relatively weak industry.

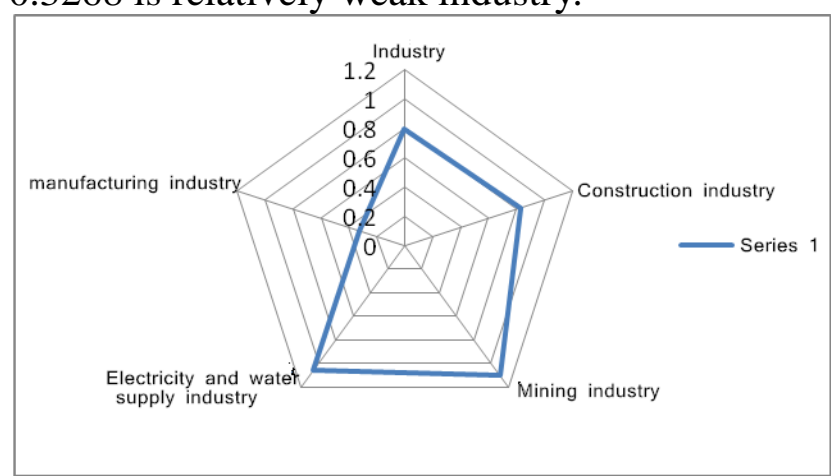

(4) of the third industry internal structure analysis

The internal structure of the tertiary industry by below to reflect, in general most industries in the tertiary industry location entropy are less than 1, the financial industry and transportation of location entropy and 0.1 and 0.1 , respectively to illustrate the two industries develop slowly. Accommodation and catering industry and other industries of location entropy are close, with the development of the local hot spring tourism economy and exhibition economy is closely related to the real estate industry of location entropy is less than 1, belong to the advantage industry. 


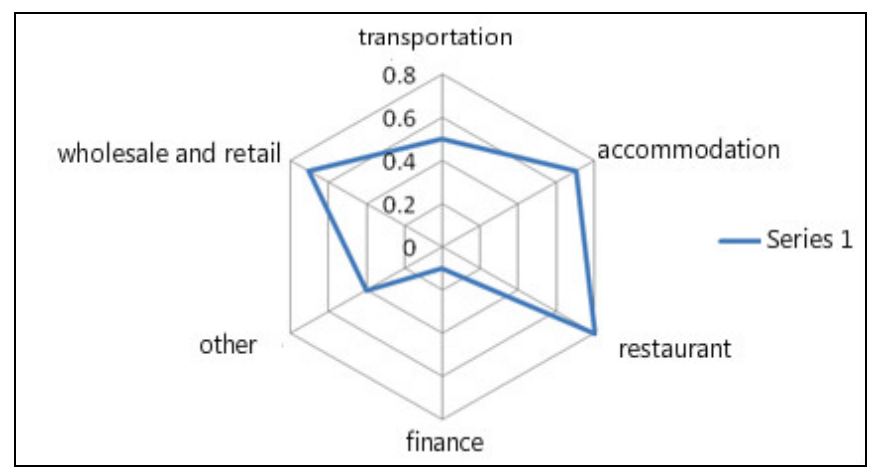

(5) internal industry comparative advantage analysis

Regional economic growth and industrialization are inseparable, Fan Jianyong through the regional gap due to speed difference of regional structure transformation, prove that since the reform and opening up regional gap widening is made up of the second industry share of the high output and non-agricultural caused by unbalanced in spatial distribution[1]. Therefore, in order to further analysis of the pros and cons of various industries, Shanghe within the industry to industry internal location entropy is calculated in a wide range of industries, the results are shown in the image below.

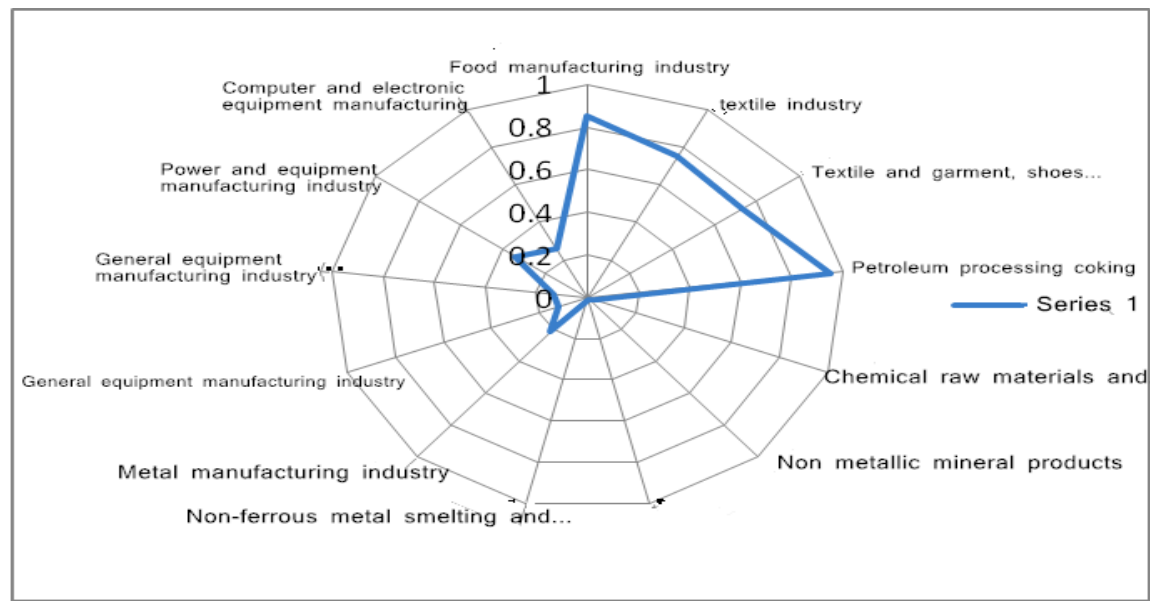

Through the above we can see that the agricultural food processing industry, oil processing and coking, textile industry has the relative development advantages, the three industry share common features: first, belongs to growth industry sector, development trend is good, have very good development potential; Second, they have good base of industrial structure, occupies an important position in the industry, contribution to the regional economic growth; Then, their growth rate is high, from the side reflects the productivity is high and has a large regional competitive advantage; Finally, they have higher degree of specialization, industry concentration degree is higher than the entire province average level, the product output is larger.

Above all it is not hard to find, in Jinan, north across the development, Shanghe) as an important part of the undertaking, shall, in the first industry focus on developing agriculture, relatively quickly, the second industry development is relatively fast.The agricultural food processing, oil, mining, textile and other industrial departments havethe relative development advantages, shall give priority to development, Shanghe third industry development is relatively backward, it has a lot of geothermal resources, can undertake geothermal development, vigorously develop tourism industry and its supporting service facilities, promoting economic development.

\section{Shanghe county economic development countermeasure analysis}

First, to aim at the harmonious development, scientific planning and resources development and utilization. Standing on the scientific development view the overall situation of height, scientific planning and resources development and utilization of the resources development and protection, cultivating new resource advantage in development, protect the natural resources at the same time, 
strictly limited extensive development and utilization of resources, actively guide intensive development and utilization of resources.

Second, on the basis of stronger competitive industries, arrangement in advance resources development and utilization. Around further enlarge, big agriculture, the advantages of the labor-intensive industries, tourism industry, give full play to the industry's competitive advantage and economic advantage, resource advantage,Ready "industrial extension"this "article",With strong with the weak, with great development pattern with a small. Around the advantage resources, give full play to the resource of attractive to capital elements such as capital, technology, talents, cultivating and developing the new competitive industries.

Third, actively undertake as the core, comprehensive introduction of capital elements. Actively undertake Jinan industry, the fundamental purpose is by means of the Jinan north across the historical opportunity, accelerate Shanghe economy faster and better development.Therefore,in the transfer industry in Jinan,according to the requirements of the scientific outlook on development, based on the sustainable development of the economy, cultivating comprehensive implementation industry and economic development and social progress. Therefore, comprehensive introduction of capital elements, especially the "soft factors" such as technology, talent, is the important measure to realize economic development and social progress, is the key in Jinan business too.

Fourth, to undertake industrial transfer of industry to guide and support. First, to the north of the Yellow River Jinan industry transfer funds, technology and talents, not only Shanghe this location choice, often can be after comparing several preferential investment, if Shanghe local governments do not develop policies to attract capital, technology and talent, will not be able to grasp the historical opportunity of Jinan north across, and promote the prosperity of the local economy. Second, seize opportunities, improve the occasion, comply with the requirement of industry transfer, planning, industrial transfer is orderly. Comprehensive analysis of comparative advantages, combined with industrial structure adjustment, focus on the local pillar industries, industrial guidance of Jinan city industrial shift to Shanghe, to form the characteristic economy, improve the level of industry, optimize the industrial structure, speed up the development of pillar industries. Third, formulate preferential policies to create Jinan between enterprises and the enterprises in Shanghe two-way investment, equity participation, service opportunities, the introduction of new technologies, develop new products and expand the market. Actively improve the investment environment, especially to improve the investment service system, to accelerate the approval process, undertake transfer of industries to create good conditions for industry transfer.

\section{References}

[1] Fan Jianyong.The gap evolution in China and its structure decomposition, The management of the world, no. 7,2002

[2] Yuan Li. The Research of Relationship Between New Product Development and External Dual Capabilities and Organizational Learning[A]. The Chinese Association of Science of Science and S\&T Policy Research, The Chinese Professional Committee of Technology and Innovation management. Proceedings of the 5th Chinese Conference on Science Technology Policy and Manage Academic[C]. The Chinese Association of Science of Science and S\&T Policy Research, The Chinese Professional Committee of Technology and Innovation management:, 2009:28.

[3] Zhi Cui, Bo Yu, Kun Cui. The Empirical Research on the Impact Factors of the Absorptive Capacity of Enterprise[J]. Journal of HIT(Social Science Edition),2008,01:127-132.

[4]Xiaojing Chen, Mingjie Rui. An Empirical Research in the Innovation Factors of Tacit Knowledge[J]. Statistics and Decision, 2007, 21:85-90.

[5]Mingjie Qui, Yan Zhang. The research review of modular organization theory[J]. Contemporary Finance \& Economics, 2008, 03:122-128. 